\title{
Thermal Conductivity Performance of Kenaf Core - Quarry Dust Brick (KCQB)
}

\author{
A. H. Hassan,", Z. Ahmad', M. F. Arshad ${ }^{2}$, N. A. Salehuddin'², M. Z. Mohd Nor ${ }^{3}$ \\ ${ }^{1}$ National Kenaf and Tobacco Board (State of Johor), 81200 Johor Bahru, Johor, Malaysia \\ ${ }^{2}$ School of Civil Engineering, College of Engineering, Universiti Teknologi MARA, 40450 Shah Alam, Selangor, Malaysia \\ ${ }^{3}$ National Kenaf and Tobacco Board (State of Pahang), 25200 Kuantan, Pahang, Malaysia
}

Received January 15, 2021; Revised July 27, 2021; Accepted August 9, 2021

\section{Cite This Paper in the following Citation Styles}

(a): [1] A. H. Hassan, Z. Ahmad, M. F. Arshad, N. A. Salehuddin, M. Z. Mohd Nor, "Thermal Conductivity Performance of Kenaf Core - Quarry Dust Brick (KCQB)," Civil Engineering and Architecture, Vol. 9, No. 5A, pp. 108 120, 2021. DOI: 10.13189/cea.2021.091313.

(b): A. H. Hassan, Z. Ahmad, M. F. Arshad, N. A. Salehuddin, M. Z. Mohd Nor (2021). Thermal Conductivity Performance of Kenaf Core - Quarry Dust Brick (KCQB). Civil Engineering and Architecture, 9(5A), 108 - 120. DOI: 10.13189/cea.2021.091313.

Copyright@2021 by authors, all rights reserved. Authors agree that this article remains permanently open access under the terms of the Creative Commons Attribution License 4.0 International License

\begin{abstract}
Rapid development has led to increasing demand for sand, which is the main source of sand brick and other construction purposes. High demand and environmental issues contribute to the shortage of resources and continuous increase in the cost of the material. In order to overcome this matter, there is a need for replacement materials as alternative resources for fine aggregate. In Malaysia, a renewable resource from biomass that can easily be converted to aggregate material is the woody part of kenaf. It is commonly called kenaf core and is available in abundance after the processing of kenaf stem for bast fiber production. The investigations cover thermal conductivity, compressive strength, density, and porosity of Kenaf Core Quarry Dust Bricks (KCQB). Nine (9) types of samples of bricks, plates, and brick wall were prepared by varying the kenaf core contents. M1, M2, M3, and M4 were used as control samples while M5, M6, M7, M8, and M9 were variable samples with different percentages of kenaf core from $5 \%$ to $25 \%$. Quarry dust was fixed at $75 \%$ for every variable mix and the balance of $25 \%$ sand was replaced by kenaf core at $5 \%$ intervals, respectively, until the portion of sand was zero. Based on all properties studied, it is found that the addition of kenaf core affected the thermal conductivity, density, porosity, and compressive strength value. Based on all the properties studied, the addition of kenaf core affected the compressive strength, density, porosity, and thermal conductivity. The compressive strength and density decreased as the kenaf core increased. However, the inclusion of kenaf core
\end{abstract}

resulted in higher porosity. Meanwhile, the addition of a kenaf core from 5\% to 25\% as sand replacement improved the thermal conductivity values from $0.63 \mathrm{~W} / \mathrm{m} \cdot \mathrm{K}$ to 0.42 $\mathrm{W} / \mathrm{m} \cdot \mathrm{K}$.

Keywords Kenaf Core, Thermal Conductivity, Density, CQB, Replacement

\section{Introduction}

Tropical climate countries like Malaysia are exposed to high temperatures outside the buildings on certain days. Due to the high temperature exposure, the use of mechanical ventilation and air-conditioning are common solutions that provide and maintain the comfort-cool environment in a room or building interior [1]. Therefore, it can be observed that the energy consumption in buildings is extremely high hence, increasing the cost of cooling the spaces in the long run. One of the contributing factors of this matter is the material used in the building of the walls, which does not function well as a thermal insulator [2]. The thermal insulation of a building provides a comfortable environment for residents by blocking direct heat from the sunlight and maintaining internal cooling energy consumption. The continuing need to conserve energy has resulted in mandated requirements for the thermal performance of construction. 
The heat is transferred by conduction, radiation, and convection from a warmer space to a cooler space until the temperatures of both spaces are the same. In buildings, heat loss by conduction is typically the most significant method of heat transfer through the wall, window, door, floor, and roof. From these elements, the wall is found to be the major element that contributes to heat loss. It can be reduced through thermal insulation with appropriate construction techniques and choice of materials.

Nowadays, energy shortage and pollution have become the main problems in society. Modern building materials that have high energy costs and $\mathrm{CO}_{2}$ emissions should be replaced by sustainable and environmental building materials, which are abundant and inexpensive. Awareness of green technology products and applications is increasing year-over-year. The usage of renewable resources has been promoted to all strategic sectors, including the construction industries for good environmental effects.

Bricks are defined as small rectangular blocks typically made from hard material, which are used in walling units and houses [3]. Bricks are widely used for load bearing and non-load bearing walls around the world. For decades, conventional bricks have been mainly produced from clay with high temperature kiln firing or from Ordinary Portland Cement (OPC). Nowadays, there are many types of bricks that are used in construction industries, such as sand brick, concrete brick, and composite brick rather than clay brick.

In Malaysia, sand brick is commonly used because of the availability of natural sand and the competitive price as compared to clay brick. However, rapid development has led to an increase in demand for sand, which is the main source of sand brick and other construction purposes. High demand and environmental issues contribute to the shortage of resources. From an economic standpoint, high demand together with low supply will skyrocket the price of sand [4]. In order to overcome this matter, there is a need for replacing the materials as alternative resources for fine aggregate, such as agriculture, industrial, mining, and quarrying waste. A renewable resource from biomass that can easily be converted to aggregate material is the woody part of kenaf. It is commonly called kenaf core and is available in abundance after the processing of kenaf stem for bast fiber production.

Kenaf (Hibiscus cannabinus L) is a warm season annual fiber crop closely related to cotton and jute. This herbaceous plant can be grown under a wide range of weather conditions. It can be found in Southern Asia and can grow approximately $3 \mathrm{~m}$ to $4 \mathrm{~m}$ within five months [5]. Kenaf has received attention from many researchers as a cheap, renewable, recyclable, and biodegradable alternative to synthetic polymers [6]. It is made up of an inner woody core $(60 \%)$ and an outer fibrous bark (30-40\%) surrounding the core [7]. After the decorticating and grinding process, the particle shape and surface texture of the kenaf core was observed to be almost similar to fine aggregate and can replace sand.

Besides kenaf core, quarry dust is also an under-utilized by-product produced during the crushing process of aggregates at quarries that are dumped to landfill. It can be an economical substitute for the river sand because this material is usually outlined as sediment, tailing, or different non-voluble waste subject material after the extraction and processing of rocks [8]. This industrial waste might contribute to serious environmental pollution if not well-managed $[9,21]$. Quarry dust is recommended as an alternative fine aggregate in brick \& block production due to its nearly identical performance to conventional river sand [10]. The combination of Kenaf core and quarry dust is observed to have great potential as aggregate replacement material for sand. However, the study on the combination of quarry dust and kenaf core as aggregate replacement in brick production is still limited, especially for thermal conductivity. This data is very important to prove that this combination of materials can be used as a thermal insulator for buildings, as well as other properties, such as compressive strength, density, and porosity.

The thermal conductivity of a material is its ability to conduct heat [11]. Good bricks should have a low thermal conductivity value so that buildings can keep cool from the hot weather outside. Therefore, the information on the thermal conductivity is also an important criterion besides maintaining good mechanical and durability properties of bricks.

Compared with the mechanical properties, fewer studies on the thermal property of lignocellulosic sand cement brick have been reported so far. A study on the thermal conductivity of sand-cement blocks incorporated with different proportions of kenaf fiber as an additive found that there is improvement in the block with lower thermal conductivity value [1]. A study on thermal conductivity of lime/cement stabilized hollow and plain earth blocks by the guarded hot box method indicated that the thermal conductivity is lowest for lime-stabilized soil building blocks [12]. The thermal conductivity of earth bricks consists of soil, cement, gypsum, and straw; the results showed that the addition of straw fiber positively improved the thermal properties and the thermal conductivity slightly decreased as compared to bricks without reinforcement fibers [13]. Therefore, the inclusion of natural resources from agriculture was found to reduce the thermal conductivity of the particular brick. Besides maintaining good mechanical and durability properties of bricks, the information on the thermal conductivity is an important criterion to be investigated. This paper represents the study on the effect of kenaf core contents as aggregate replacement material for thermal conductivity, compressive strength, density, and porosity of KCQB. It was found that the addition of a kenaf core had an advantage that helped reduce the thermal conductivity value of brick for better thermal insulator properties with 
lightweight features.

\section{Materials and Methods}

\subsection{Materials}

In this study, five (5) types of materials were prepared, such as kenaf core, sand, quarry dust, Ordinary Portland Cement (OPC), and water.

Kenaf core is obtained from the National Kenaf and Tobacco Board's Processing Centre located at Rompin, Pahang. In the factory, the kenaf core was separated from kenaf fiber by using a mechanical separating line. From the processing output, the size of the kenaf core produced is not uniform and could reach up to $70 \mathrm{~mm}$. Then, the kenaf core was grinded using a grinder machine to produce a smaller size below $3 \mathrm{~mm}$. Quarry dust was supplied by a granite quarry located at Rawang. Sand was supplied by a local supplier from Shah Alam. The properties of the kenaf core used are presented in Table 1 [14]. The density of the kenaf core is $180 \mathrm{~kg} / \mathrm{m}^{3}$ on average. Moisture content of the kenaf core remained in the range of $3 \%-6 \%$.

Table 1. Properties of Kenaf Core

\begin{tabular}{cc}
\hline Properties & Kenaf Core \\
\hline Maximum size $(\mathrm{mm})$ & 3 \\
Moisture content $(\%)$ & $3-6$ \\
Unit Weight $\left(\mathrm{kg} / \mathrm{m}^{3}\right)$ & 180 \\
Fineness Modulus Value & 1.5 \\
Absorption capacity & 120
\end{tabular}

The properties of quarry dust used are presented in Table 2 [14]. The size of the quarry dust used passed the 5 $\mathrm{mm}$ sieve. Before being used, it was properly stored to keep it in good condition. The density of the quarry dust is $1,800 \mathrm{~kg} / \mathrm{m}^{3}$.

Table 2. Properties of Quarry Dust

\begin{tabular}{cc}
\hline Properties & Quarry Dust \\
\hline Maximum size $(\mathrm{mm})$ & 5 \\
Moisture content $(\%)$ & $3-5$ \\
Unit Weight $\left(\mathrm{kg} / \mathrm{m}^{3}\right)$ & 1,800 \\
Fineness Modulus Value & 2 \\
Absorption capacity & 3 \\
\hline
\end{tabular}

Similar to quarry dust, the river sand used passed the 5 $\mathrm{mm}$ sieve. Table 3 shows the properties of sand used in this research [14]. The sand was graded according to ASTM C33/C33M-16e1. The sand obtained was cleaned, dried, and free from impurities.
Table 3. Properties of Sand

\begin{tabular}{cc}
\hline Properties & Sand \\
\hline Maximum size $(\mathrm{mm})$ & 5 \\
Moisture content $(\%)$ & $3-5$ \\
Unit Weight $\left(\mathrm{kg} / \mathrm{m}^{3}\right)$ & 1,600 \\
Fineness Modulus Value & 2.85 \\
Absorption capacity & 2.4 \\
\hline
\end{tabular}

The cement used was from Tasek Corporation Berhad, which meets the requirement specification for Portland cement, MS 522: 1989. The OPC was sealed and stored in a sheltered area to maintain the quality of the product. Table 4 shows the chemical composition and physical properties of OPC used in this research. Tap water was used for the mixing of cement paste in determining its fresh and hardened properties. The treated water was supplied by a concession company owned by the state of Selangor. The water cement ratio used was 0.6.

Table 4. Chemical Composition and Physical of OPC Supplied by Tasek Corporation Berhad

\begin{tabular}{ccc}
\hline \multicolumn{3}{c}{ Chemical Components [Oxide Composition (\%)] } \\
\hline Calcium Oxide & $\mathrm{CaO}$ & 64.64 \\
Silicon Dioxide & $\mathrm{SiO}_{2}$ & 21.28 \\
Aluminium Trioxide & $\mathrm{Al}_{2} \mathrm{O}_{3}$ & 5.6 \\
Ferric Trioxide & $\mathrm{Fe}_{2} \mathrm{O}_{3}$ & 3.36 \\
Magnesium Oxide & $\mathrm{MgO}$ & 2.06 \\
Sulphate & $\mathrm{SO}_{3}$ & 2.14 \\
Total Alkalis & $\mathrm{N}_{2} \mathrm{O}$ & 0.05 \\
Insoluble Residue & $\mathrm{IR}$ & 0.22 \\
Loss of Ignition & $\mathrm{LOI}$ & 0.64 \\
\hline \multicolumn{2}{c}{ Physical Properties } \\
\hline Relative Density & $\mathrm{mg} / \mathrm{m}^{3}$ & 3.15 \\
Fineness & $\mathrm{m}^{2} / \mathrm{kg}$ & 340 \\
\hline
\end{tabular}

\subsection{Mix Proportions}

Nine (9) types of samples of bricks and plates were prepared by varying the kenaf core contents and they were denoted as M1 for Sand Brick 100\% (S), M2 for Quarry Dust Brick 100\% (QD), M3 for Kenaf Core Brick 100\% (KC), M4 for Quarry Dust 75\% (75QD), M5 for Kenaf Core 5\% (5KC), M6 for Kenaf Core 10\% (10KC), M7 for Kenaf Core $15 \%(15 \mathrm{KC})$, M8 for Kenaf Core $20 \%$ $(20 \mathrm{KC})$, and M9 for Kenaf Core 25\% (25KC). M1, M2, M3, and M4 were used for control samples while M5, M6, M7, M8, and M9 were variable samples with different percentages of kenaf core $5 \%$ to $25 \%$. The ratio of cement and material remained consistent at 1:6 for all types of the mix. Water cement ratio was constant at 0.6. For this research, quarry dust was fixed at $75 \%$ for every variable of the mix and the balance of $25 \%$ sand was replaced by kenaf core at 5\% intervals, respectively, until the portion of sand is $0 \%$ as stated in Table 5 . 
Table 5. Mix Design Proportions of KCQB

\begin{tabular}{|c|c|c|c|c|}
\hline \multirow{2}{*}{ Mixes } & OPC & Sand & Quarry dust & Kenaf core \\
\cline { 2 - 5 } & $\boldsymbol{\%}$ & $\boldsymbol{\%}$ & $\boldsymbol{\%}$ & $\boldsymbol{\%}$ \\
\hline M1 (S) & 100 & 100 & - & - \\
\hline M2 (QD) & 100 & - & 100 & - \\
\hline M3 (KC) & 100 & - & - & 100 \\
\hline M4 (0KC) & 100 & 25 & 75 & - \\
\hline M5 (5KC) & 100 & 20 & 75 & 5 \\
\hline M6 (10KC) & 100 & 15 & 75 & 10 \\
\hline M7 (15KC) & 100 & 10 & 75 & 15 \\
\hline M8 (20KC) & 100 & 5 & 75 & 20 \\
\hline M9 (25KC) & 100 & 0 & 75 & 25 \\
\hline
\end{tabular}

\subsection{Samples Preparation}

There were three (3) types of samples prepared to determine the objective set in this study. Firstly, the samples were cast in mould brick. Then, the samples were cured at normal room temperature for 3, 7, and 28 days. After that, the compressive strength and density tests were conducted in the Concrete Laboratory. Meanwhile, the porosity test was conducted in the Non-Destructive Testing (NDT) Laboratory, School of Civil Engineering, College of Engineering, UiTM Shah Alam.

Secondly, the samples were cast on the plate using the same type of mix. Then the samples were also cured for 28 days at normal room temperature. Then, the thermal conductivity test was conducted in the Concrete Laboratory, School of Civil Engineering, College of Engineering, UiTM Shah Alam using the Guarded Hot Plate method. Lastly, the third sample was brick walls. The walls were constructed at the Thermal Laboratory Building, Faculty of Architecture, Planning and Surveying, UiTM to measure the thermal conductivity by using the Guarded Hot Box testing method.

Besides the thermal conductivity test, which is the main objective of study, compressive strength, density, and porosity tests were also conducted for different mixed designs, including control samples.

\subsection{Compressive Strength Measurements}

The purpose of the compressive strength test is to determine the maximum stress and load that the bricks can sustain under a gradually applied load. This test is prescribed by BS EN 772-1. In this study, the compressive strength only tested the samples that were cured at normal room temperature for 3, 7, and 28 days. For each type of mix, six replicate samples were prepared. The compression tests were conducted using the Universal Testing Machine (UTM-1000) in the Concrete Laboratory,
School of Civil Engineering, College of Engineering, UiTM Shah Alam.

\subsection{Density \& Porosity Measurements}

Density expresses the weight of material divided by the volume it occupies. The volume of brick was obtained by multiplying the width, length, and height of the brick. The weight was measured by a mass balance machine.

Porosity tests were conducted to determine the percentage of porosity of the brick. The porosity test was determined based on the age of curing which were 3,7 , and 28 days in accordance with the method developed by RILEM: CPC 11.3, Absorption of Water by Immersion Under Vacuum Test Procedure (1991).

The porosity test was conducted using a vacuum desiccator. This equipment is located in the Non-Destructive Testing (NDT) Laboratory, School of Civil Engineering, College of Engineering, UiTM Shah Alam.

\subsection{Thermal Conductivity Tests}

In this study, thermal conductivity tests were conducted on two (2) types of samples, which are plates and brick walls using different methods of testing. The testing for plates was conducted to measure the thermal conductivity of the material, while the testing for brick walls aimed to measure the thermal conductivity of bricks.

The thermal conductivity of the material used in brick walls was tested by using the Guarded Hot Plate method. This equipment was located in the Non-Destructive Testing (NDT) Laboratory, School of Civil Engineering, College of Engineering, UiTM Shah Alam. The specimen was placed in between (2) two plates. The upper plate was heated, and the below sample was cooled. The equipment was operated using computer controls and the thermal conductivity value was recorded in the data reporting software installed. The test was carried out in accordance with ASTM C177: Standard Test Method for Steady-State Heat Flux Measurements and Thermal Transmission Properties by Means of the Guarded Hot Plate Apparatus as shown in Figure 1.

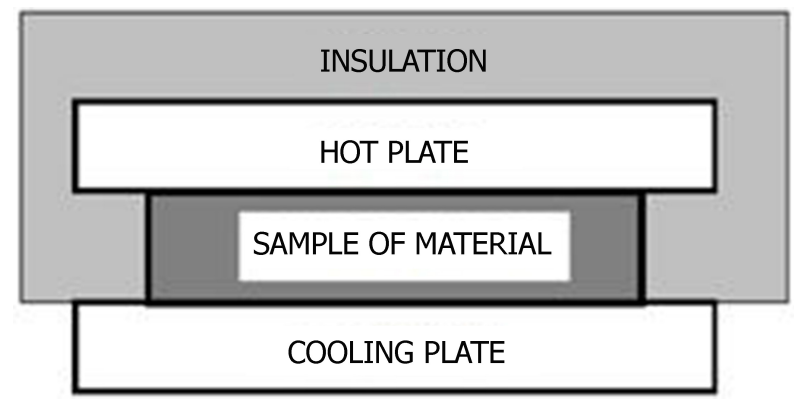

Figure 1. Schematic Diagram of Guarded Hot Plate Apparatus 


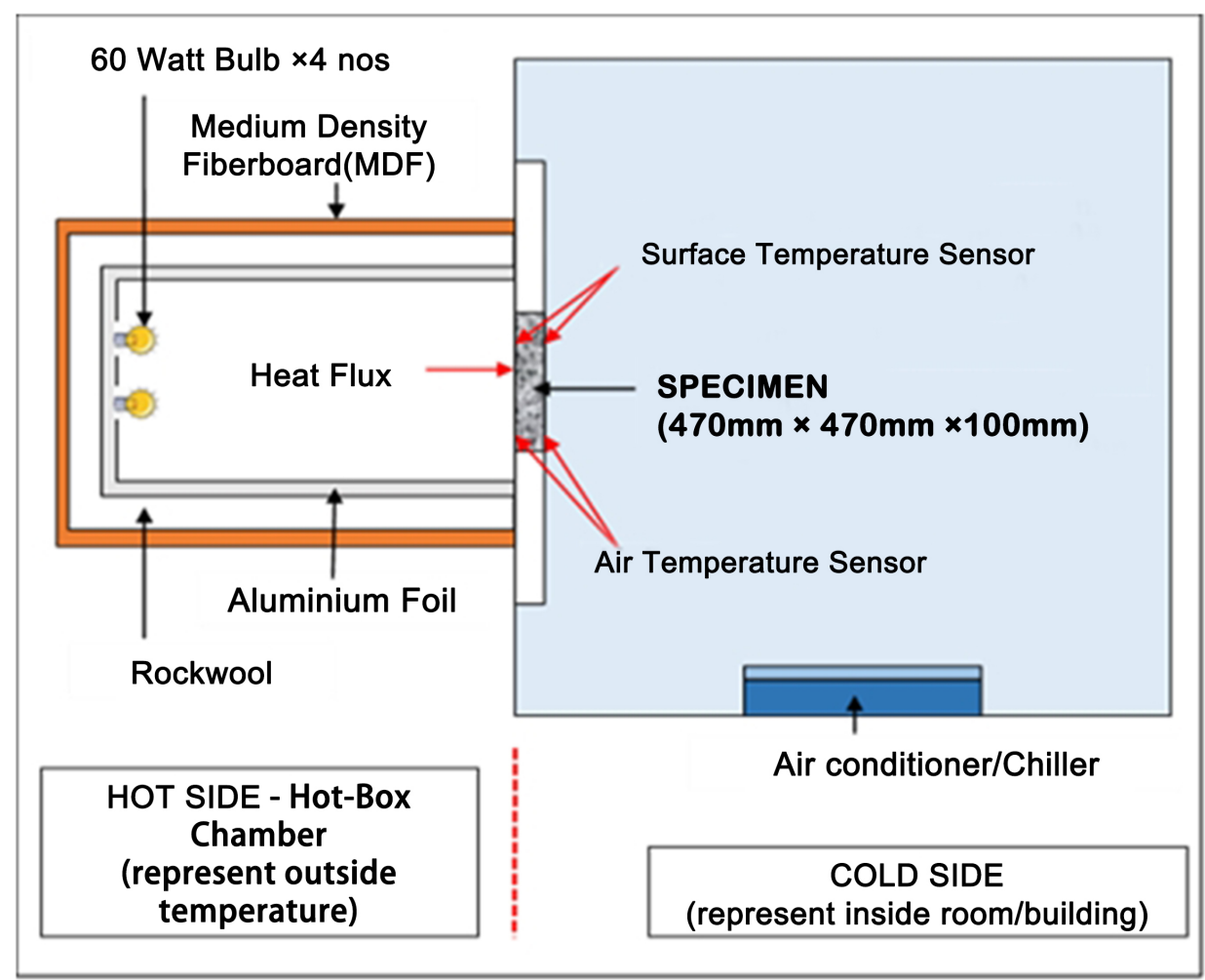

Figure 2. Schematic Diagram of Hot-Box Set Up

The thermal conductivity of the brick was tested using the Hot-Box method as per stated in BS EN ISO 8990: 1996: Thermal insulation. Determination of Steady-State Thermal Transmission Properties - Calibrated and Guarded Hot Box. The size of the brick wall was $470 \mathrm{~mm}$ $\mathrm{x} 470 \mathrm{~mm} \times 100 \mathrm{~mm}$. Wall panels with different percentages of kenaf core and fine aggregate were tested to find the value of thermal conductivity coefficient, known as $\mathrm{K}$-value. The unit measurement of the thermal conductivity is in $\mathrm{W} / \mathrm{m}^{\circ} \mathrm{C}$ and converted to $\mathrm{W} / \mathrm{mK}$ for synchronization.

Thermal conductivity was measured through a brick wall along a length of $100 \mathrm{~mm}$, which is similar to the brick's width. This method was run under the steady-state condition (controlled environment) in which the temperature was kept constant throughout the test. Figure 2 illustrates the schematic diagram of the hot-box set up in this study.

Three (3) types of sensors were used to conduct the test. Two (2) sets of sensors for surface and air temperature on both the hot and cold sides. Meanwhile, a heat flux plate sensor was positioned on the sample facing the hot side compartment. The sensors were then connected to a multi-channelled data logger (E-log). A laptop was connected to the data logger before the test began. The laptop remained on to ensure all data measured from the data logger was transferred to the computer from time to time. The data obtained were recorded to calculate the thermal conductivity of the material studied. The data was received every five minutes on the laptop. The testing was carried out in six hours for a single brick wall. The thermal conductivity values of the brick wall were calculated based on the data of hot air $\left({ }^{\circ} \mathrm{C}\right)$, hot area $\left({ }^{\circ} \mathrm{C}\right)$, heat flux $\left(\mathrm{W} / \mathrm{m}^{3}\right)$, cold air $\left({ }^{\circ} \mathrm{C}\right)$, and cold area $\left({ }^{\circ} \mathrm{C}\right)$ recorded.

\section{Discussion}

\subsection{Compressive Strength}

Compressive strength is the main parameter studied in order to quantify the performance of newly developed bricks with different compositions. From Figure 3, it can be observed that M1 achieved the highest value of compressive strength after 28 days of curing, while M3 recorded the lowest value of compressive strength by $99.1 \%$ reduction. This shows that the use of $100 \%$ kenaf core fine aggregate is impossible. There was no significant difference in the compressive strength for M2 
and M4. For environmental benefit, the brick can be produced using $100 \%$ quarry dust without sand. To see the effect of the kenaf core as sand replacement, the sand portion in M4 was replaced by the kenaf core at 5\% intervals, namely M5 (with 5\%), M6 (10\%), M7 (15\%), M8 (20\%), and M9 (25\%). It can be seen that as the percentages of the kenaf core increased from $5 \%$ to $25 \%$, the compressive strength decreased exponentially.

So, it can be determined that the addition of the kenaf core decreases the compressive strength. A possible reason for strength reduction is because the kenaf core as the aggregate in the mix, does not react completely with the cementitious materials and other aggregate materials, resulting in lower bonding and decreasing the compressive strength $[15,16]$.

However, all compressive strength values were still higher than the permissible average compressive strength for the non-load bearing wall as specified by the Malaysian Public Works Department which is $5.2 \mathrm{~N} / \mathrm{mm}^{2}$. Up to this point of the study, 25\% kenaf core replacement of sand is the most percentage in a test that can be added. A percentage higher than $25 \%$ may result in lower compressive strength and inability to comply with the minimum permissible value.

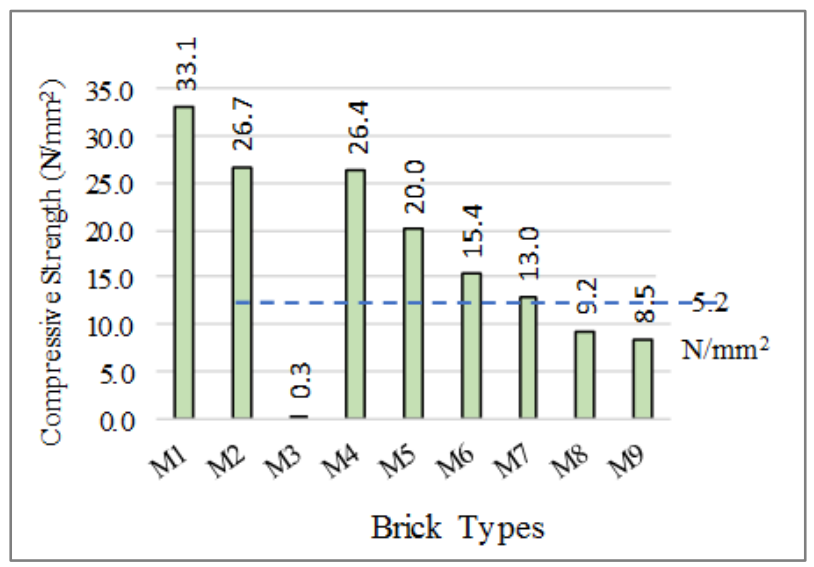

Figure 3. Compressive Strength of Bricks

Figure 4 shows the relationships between age and compressive strength for all types of bricks studied at 3, 7, and 28 days. The figures show that strength development for most types of bricks improves with the increase in days of curing. From the graph, it shows that the control specimen (M4) achieved the highest compressive strength value of $22.9 \mathrm{~N} / \mathrm{mm}^{2}$ after 3 days of curing, while the control specimen (M1) achieved the highest compressive strength value of $28.4 \mathrm{~N} / \mathrm{mm}^{2}$ and $33.14 \mathrm{~N} / \mathrm{mm}^{2}$ after 7 days and 28 days of curing, respectively, as compared to the other bricks. From this result, it can also be seen that M1 gets the highest strength compared to M2, M3, and M4 for the control specimen after 7 days and above. The normal sand-cement brick still has the highest compressive strength when compared with other combinations.

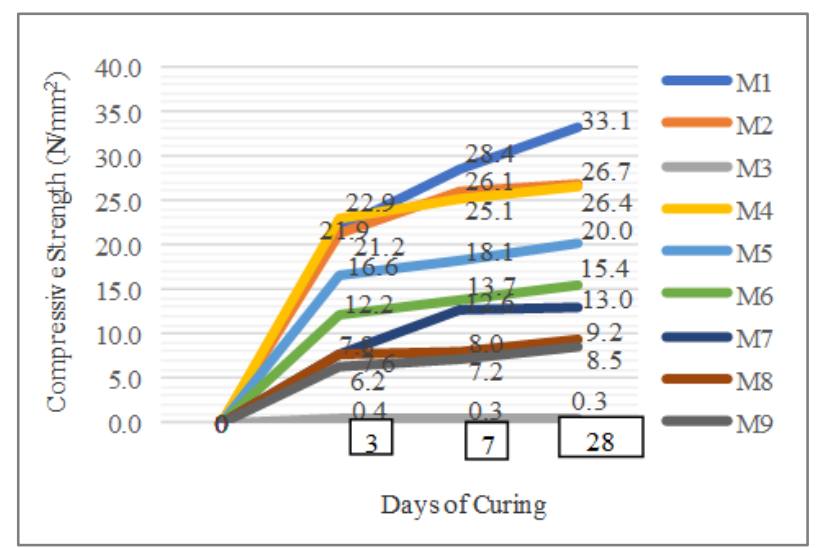

Figure 4. Compressive Strength at 3, 7, 28 Days for Difference Types of Brick

Meanwhile, M3 shows the lowest compressive strength value, which is $0.4 \mathrm{~N} / \mathrm{mm}^{2}, 0.3 \mathrm{~N} / \mathrm{mm}^{2}$, and $0.3 \mathrm{~N} / \mathrm{mm}^{2}$ for 3,7 , and 28 days of curing, respectively, as compared to all types of bricks. This shows that the kenaf core cannot be used as an aggregate in $100 \%$ replacement for sand. At 28 days of curing, the compressive strength of M1 is $19.4 \%, 99.1 \%$, and $20.3 \%$ higher than M2, M3, and M4, respectively.

The strength development of M4 has increased consistently for 3, 7, and 28 days of curing as well as M2. At 28 days, there was no significant difference in the compressive strength for M2 and M4, which means that the sand can be replaced with $100 \%$ quarry dust. With that being said, the objective of this study to reduce the dependency on sand has been achieved.

The strength development of M5, M6, M7, M8, and M9 seemed to be affected by the replacement of different percentages of the kenaf core. The higher the percentage of replacement, the lower the compressive strength.

\subsection{Density}

Figure 5 presents the density of 9 series of bricks at 3,7 and 28 days of curing.

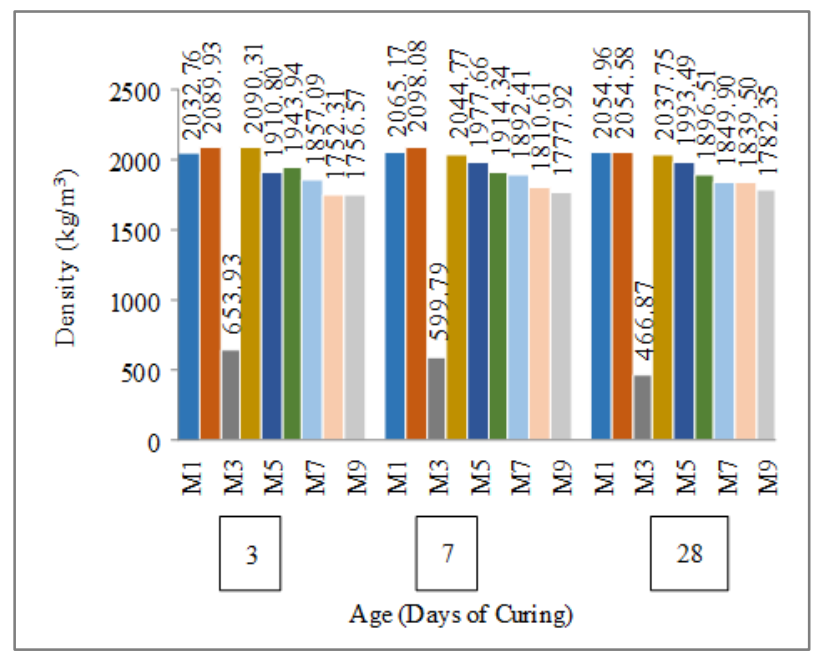

Figure 5. Density Development of Bricks 
Based on the results, it clearly shows that the value of density decreases with the increase in the kenaf core percentage. At 28 days of curing, M9 recorded the lowest density among the variable samples, as compared to control samples M2 and M4 by $13.2 \%$ and $12.5 \%$ reduction, respectively. $\mathrm{M} 3$ recorded the lowest density of $466.87 \mathrm{~kg} / \mathrm{m}^{3}$ among the studied bricks. There were no significant differences in the densities for M1, M2, and M4. The reason is that the properties of aggregates are almost similar and produced from natural minerals. The addition of the kenaf core from $5 \%$ to $25 \%$ decreased the density of bricks by $2.2 \%$ to $12.5 \%$ and made the brick light in weight. The density of M2 was also almost $340 \%$ higher than M3 as the density of the kenaf core was low: $210 \mathrm{~kg} / \mathrm{m}^{3}$, as studied in the previous research [17].

Overall, the result was similar to the research done on the density of Sand Cement Blocks incorporated with kenaf fiber from $0 \%$ to $5 \%$, where the density of the blocks was reduced from $2,142.56 \mathrm{~kg} / \mathrm{m}^{3}$ to $1,900.83$ $\mathrm{kg} / \mathrm{m}^{3}$ when the percentage of kenaf fiber in blocks increased to $5 \%$ [2]. Besides that, the results obtained were also parallel to the study carried out on the kenaf fiber reinforced concrete block with quarry dust as fine aggregate replacement, which resulted in lower density compared to the control sample [18]. Therefore, the inclusion of the kenaf core slightly reduced the density of the KCQB which reflected the lightweight feature.

\subsection{Porosity}

The results of porosity values based on type of brick at 3,7 , and 28 days of curing are presented in Figure 6. The trend of porosity on difference mix tests could be clearly observed at 7 and 28 days. The percentage of porosity increases with the increase in the kenaf core percentage.

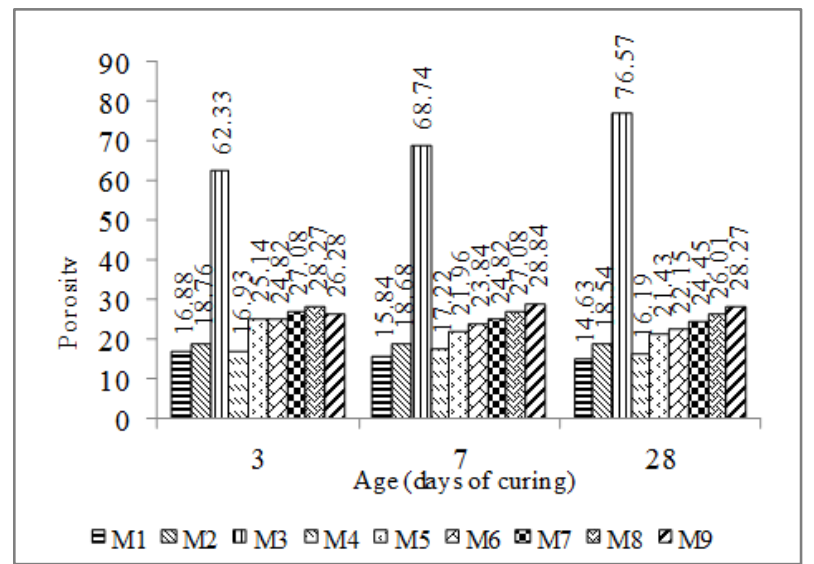

Figure 6. Porosity of Bricks at 3, 7, and 28 Days of Curing for All Brick Types

The results of the porosity test at 28 days of curing are shown in Figure 7. M3 recorded the highest percentage of porosity value among all types of bricks. Without the addition of the kenaf core, the control samples M1, M2, and M4 indicated almost the same value of porosity ranging from $14.63 \%$ to $18.54 \%$. The addition of the kenaf core from $5 \%$ to $25 \%$ in mix M5, M6, M7, M8, and M9 resulted in a linear relationship for porosity value.

All porous materials are easily exposed to chemical attacks and liable to contamination from weathering agents like rain, running water, and polluted air. In construction, the porosity of building materials is an important factor to consider with respect to its performance and applications.

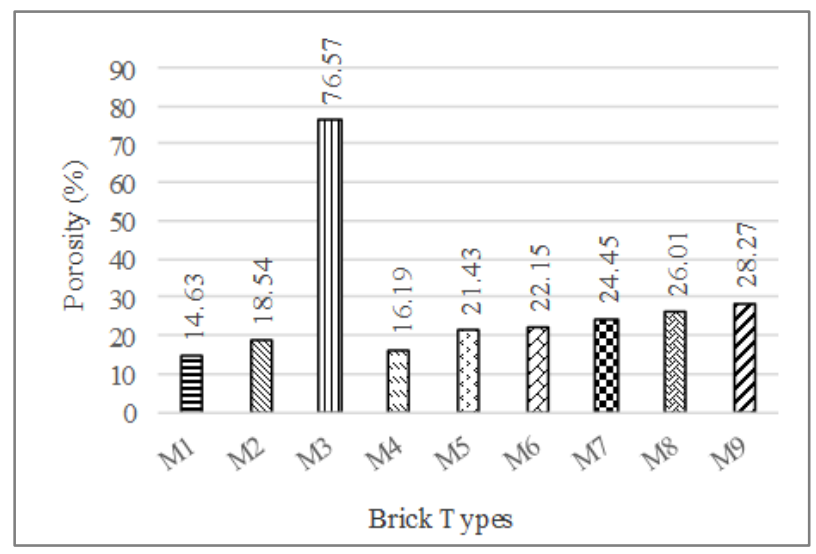

Figure 7. Porosity at 28 Days of Curing for All Brick Types

\subsection{Compressive Strength versus Density}

The correlation between compressive strength and density of the bricks is shown in Figure 8. The coefficient of determination, $\mathrm{R}^{2}$ for this relationship was 0.95 and the coefficient of correlation was 0.98 . This indicated a very close relationship between compressive strength and density of the studied bricks. The higher the density of the bricks, the higher the compressive strength of the bricks. Meanwhile, the lower percentage of the kenaf core addition resulted in higher density and compressive strength.

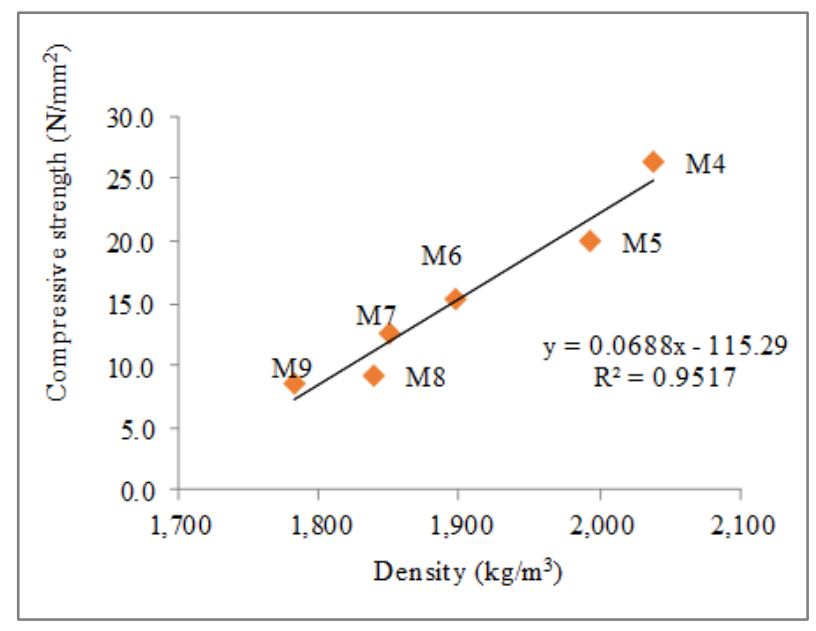

Figure 8. Compressive Strength versus Density of KCQB 


\subsection{Compressive Strength versus Porosity}

The relationship between compressive strength and porosity of the bricks is presented in Figure 9. From the linear graph, $\mathrm{R}^{2}$ for this correlation was 0.95 and the coefficient of correlation was 0.97 . Hence, the value represents a very high negative correlation between compressive strength and porosity of KCQB. The higher the porosity in the bricks, the lower the compressive strength. This was attributed to the high percentage of the kenaf core.

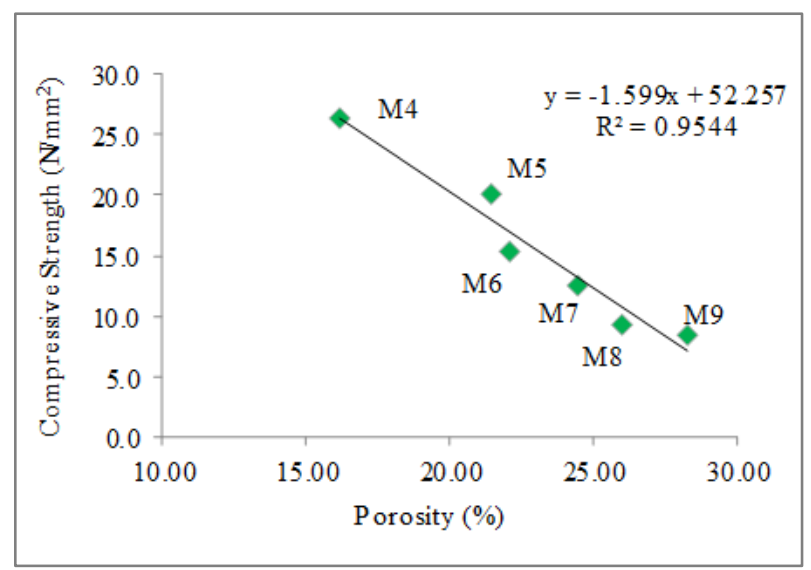

Figure 9. Compressive Strength versus Porosity of KCQB

\subsection{Porosity and Density}

The correlation between porosity and density of the bricks is shown in Figure 10. The $\mathrm{R}^{2}$ value for this relationship was 0.91 , while the coefficient of correlation was 0.95 . This linear graph reflected a very high negative correlation between porosity and density of KCQB. The higher porosity of the bricks resulted in the lower density value. The higher porosity was caused by the addition of the kenaf core in KCQB.

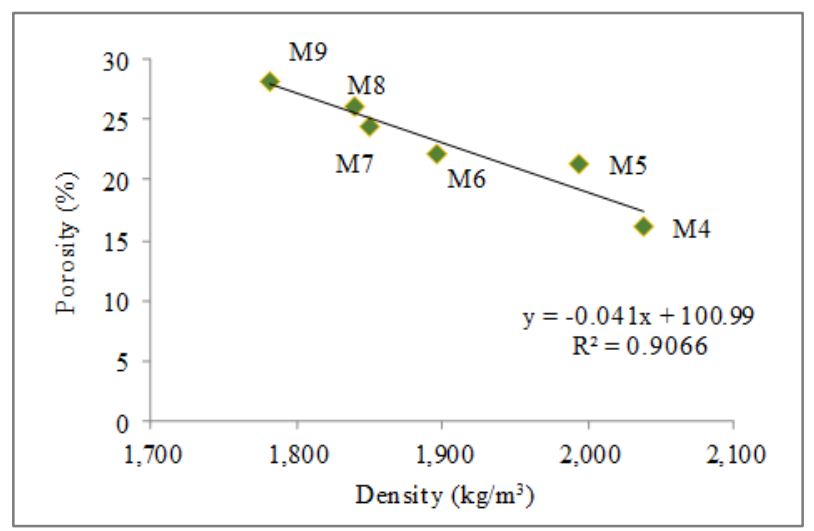

Figure 10. Porosity versus Density

\subsection{Porosity versus Density versus Compressive Strength}

The relationship between porosity, density, and compressive strength of KCQB is shown in Figure 11. From the combination graph, the higher the porosity of the bricks, the lower the density of the bricks, as well as lower in compressive strength. The higher porosity was caused by the high percentages of the kenaf core as discussed in Section 3.3. In this study, it was also shown that with the highest percentage of kenaf core, $25 \%$, it was still able to produce a brick with compressive strength 8.5 $\mathrm{N} / \mathrm{mm}^{2}$, which is higher than the minimum permissible compressive strength specified by the Public Works Department, which is $5.2 \mathrm{~N} / \mathrm{mm}^{2}$, but with lower density $\left(1,782 \mathrm{~kg} / \mathrm{m}^{3}\right)$. This has the advantage of being a lighter brick with allowable strength.

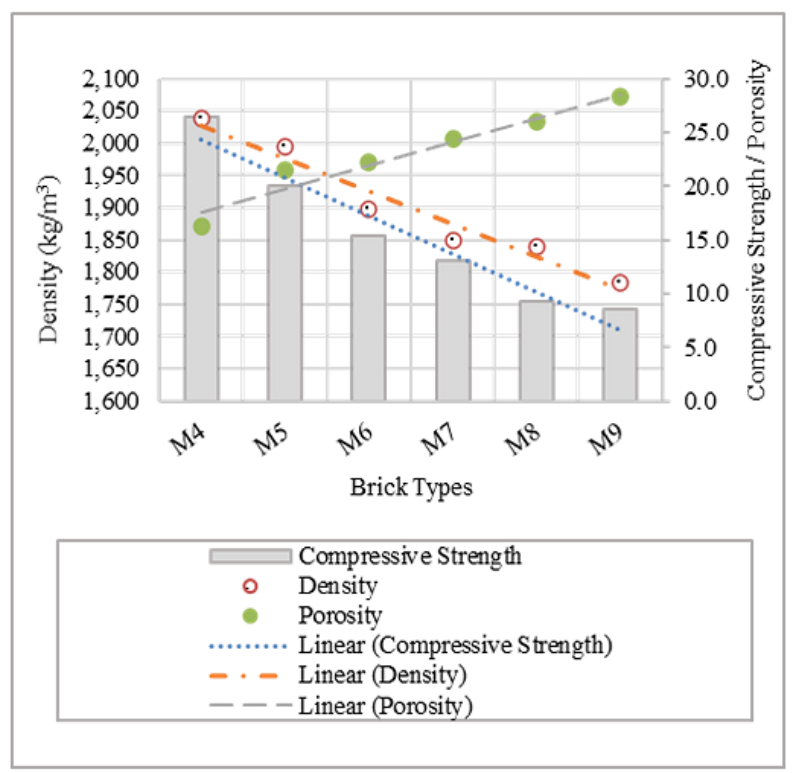

Figure 11. Porosity versus Density versus Compressive Strength

\subsection{Thermal Conductivity of Brick Material}

Now, it is important to check another property, which is the thermal property for insulation characteristics. In this study, the addition of a kenaf core aimed to improve the thermal performance of bricks. In contact with Asian countries like Malaysia which receive long sunny days, the use of a brick type with low thermal conductivity value for wall building can be an alternative to resist heat penetration from sunlight. With better insulation materials, the energy consumption to cool the entire building can be reduced. Knowledge of the mechanical and thermal properties of a material is essential for civil engineering guiding material selection for specific functions. In section 3.5 , it can be seen that as the porosity increases for all types of bricks in this study, the compressive strength decreases but still within the allowed values by the Public Works Department Malaysia.

Thermal conductivity is the measure of how easily heat flows through a specific type of material, which is said to be independent of the thickness of the material. Therefore, investigations on the thermal properties of bricks were made through two (2) types of tests, namely the guarded 
hot plate method by using the plate and the guarded hot box testing method by using a brick wall to represent the different thickness of the material.

Figure 12 shows the thermal properties of the brick material based on the hot plate method.

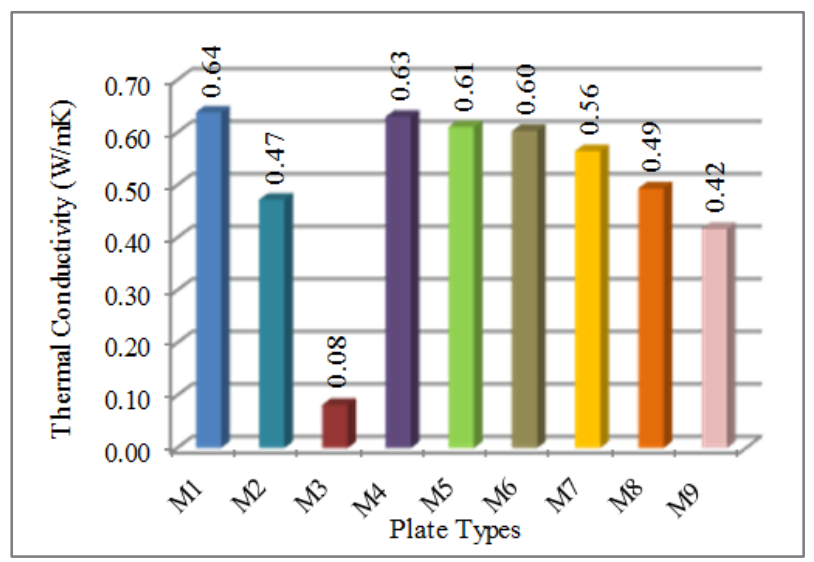

Figure 12. Thermal Conductivity of Plate for All Types of Brick

Based on the bar chart, for control samples M1, M2, $\mathrm{M} 3$, and M4, it can be seen that the thermal conductivity was the highest for M1 followed by M4, M2, and M3, respectively. The thermal conductivity of M4 with $75 \%$ quarry dust and $25 \%$ sand was $1.6 \%$ lower than M1. When the kenaf core was used to replace the sand, it can be seen that as the percentages of the kenaf core increased, the thermal conductivity decreased gradually. When compared with M1, the conductivity for M5, M6, M7, M8, and M9 decreased at $6.2 \%, 6.3 \%, 12.5 \%, 23.4 \%$, and $34.4 \%$, respectively. Also for M1, when compared with M4, the addition of the kenaf core as sand replacement reduced the thermal conductivity value and might improve the thermal resistance. Among the variable samples, M9 achieved the lowest thermal conductivity, which was also lower than M2 by $10.6 \%$. There is no significant difference when comparing all samples with M3. Compared to M4, the thermal conductivity of M9 reduced by $33.3 \%$. The higher percentage of the kenaf core resulted in lower thermal conductivity values. The finding was parallel to the research carried out on the thermal conductivity of recycled coconut fiber and crushed clay brick masonry. The addition of coconut fiber as a partial sand replacement in constant crushed clay brick reduced the thermal conductivity of the brick [19]. In general, materials with lower thermal conductivity values are known to be good thermal insulators, which provide better heat resistance for buildings.

When comparing Figure 12 and Figure 7, it can be seen that the porosity of M 3> M6 > M5 > M2 > M4 > M1. However, the order of thermal conductivity for those plates, which represents the brick material is M1 > M4 > M5 > M6 > M2 > M3. M3 has the highest porosity and the lowest thermal conductivity. The presence of higher percentages of kenaf core made the brick lighter and hence, able to retain heat with low thermal conductivity values. Another aim of this study was to utilize the waste products, namely kenaf core and quarry dust, therefore M5, M6, M7, M8, and M9 can be used as light, thermal comfort, and strong bricks for constructions.

This study shows that the thermal conductivity of bricks is mainly related to bulk density and porosity. Therefore, this study analyzed the relationship between the thermal conductivity and density, porosity, as well as compressive strength as explained in the next sections.

\subsection{Thermal Conductivity of Brick Material versus Compressive Strength}

The correlation between thermal conductivity and compressive strength of KCQB is presented in Figure 13. The coefficient of determination, $\mathrm{R}^{2}$ for this relationship was 0.71 and the coefficient of correlation was 0.84 . The linear graph indicated a high correlation between thermal conductivity and compressive strength of KCQB. The higher the compressive strength of the bricks, the higher the value of thermal conductivity. Meanwhile, the lower percentage of the kenaf core resulted in higher compressive strength. So, the addition of the kenaf core from $5 \%$ to $25 \%$ as an aggregate replacement material resulted in the lower thermal conductivity value.

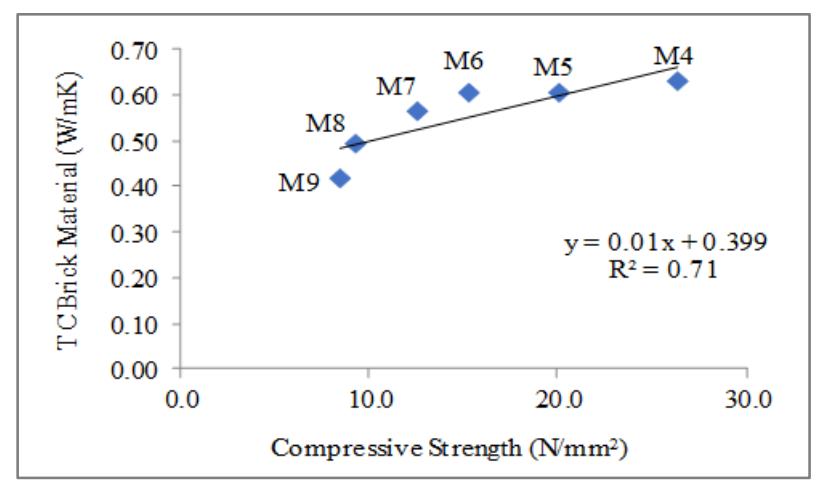

Figure 13. Thermal Conductivity of Brick Material versus Compressive Strength

\subsection{Thermal Conductivity of Brick Material versus Density}

Figure 14 presents the correlation between thermal conductivity and density of the bricks. As well as the relationship between thermal conductivity and compressive strength discussed in the previous section, the correlation between thermal conductivity and density of KCQB indicated a high relationship with the value of 0.86 coefficient of correlation. The $\mathrm{R}^{2}$ for this relationship was 0.75 as stated in the graph. The higher the density of the bricks, the higher the value of thermal conductivity and vice versa. The result was in line with previous research done on the effect of fly ash and perlite on the density and thermal conductivity of Self Compacting 
Concrete (SCC). The study found that the lower thermal conductivity of concrete was attributed to the lower density of the fly ash and perlite used [20]. Meanwhile, the lower percentage of the kenaf core addition resulted in a higher density. So, the higher percentage of the kenaf core in KCQB resulted in lower density and lower thermal conductivity value.

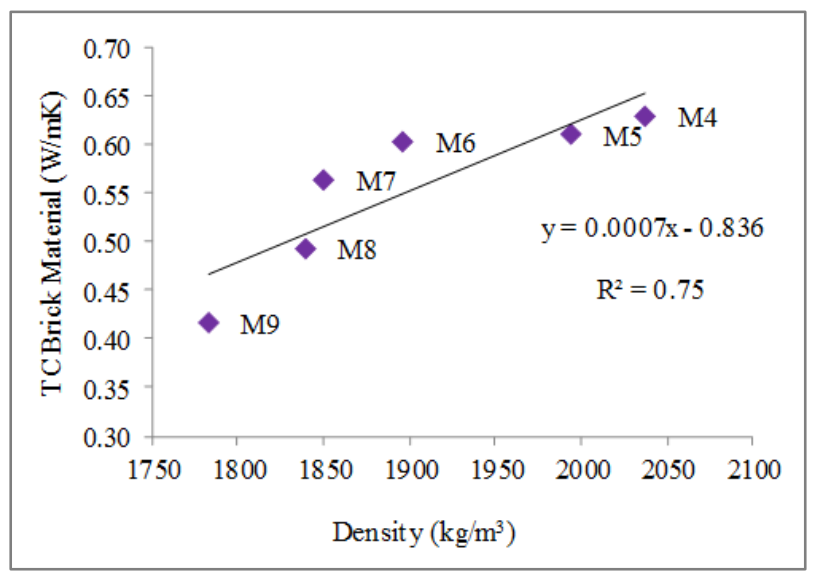

Figure 14. Thermal Conductivity of Brick Material versus Density

\subsection{Thermal Conductivity of Brick Material versus Porosity}

The relationship between thermal conductivity and porosity of KCQB is shown in Figure 15. Different from the compressive strength and density properties, the linear graph indicated a high negative correlation among the thermal conductivity and porosity of KCQB. From the graph, the $\mathrm{R}^{2}$ for this relationship was 0.79 , while the coefficient of correlation was 0.89 . The lower the porosity, the higher the thermal conductivity value. Hence, the higher percentage of the kenaf core addition resulted in a lower thermal conductivity value, but with a higher percentage of porosity.

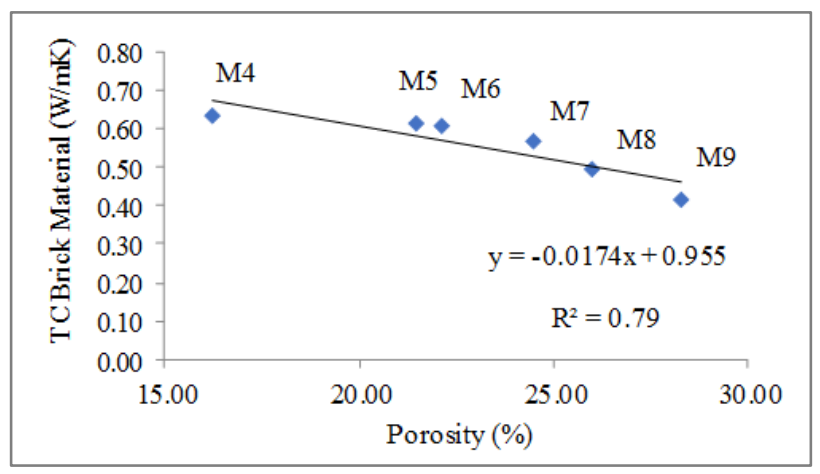

Figure 15. Thermal Conductivity of Brick Material versus Porosity

\subsection{Thermal Conductivity of Brick Wall}

Testing was conducted to measure the changes in temperature and flux difference of brick walls using the Hot Box method. Data readings for heat box (heat air, heat area and heat flux) and cold box (cold air and cold area) were recorded to calculate the thermal conductivity value. Table 5 shows the results obtained for three (3) replicate samples of the brick wall and the average thermal conductivity value calculated.

Table 5. The Value Thermal Conductivity of Wall Panels using Hot Box Method

\begin{tabular}{|c|c|c|c|c|}
\hline Wall Types & \multicolumn{4}{|c|}{ Thermal Conductivity (W/mK) } \\
\hline & Sample 1 & Sample 2 & Sample 3 & Average \\
\hline M1 & 0.85 & 0.81 & 0.83 & 0.83 \\
\hline M2 & 0.66 & 0.64 & 0.65 & 0.65 \\
\hline M3 & 0.08 & 0.13 & 0.12 & 0.11 \\
\hline M4 & 0.79 & 0.77 & 0.78 & 0.78 \\
\hline M5 & 0.75 & 0.76 & 0.78 & 0.77 \\
\hline M6 & 0.75 & 0.73 & 0.74 & 0.74 \\
\hline M7 & 0.71 & 0.71 & 0.69 & 0.70 \\
\hline M8 & 0.67 & 0.66 & 0.65 & 0.66 \\
\hline M9 & 0.64 & 0.63 & 0.62 & 0.63 \\
\hline
\end{tabular}

Among the control samples, M3 recorded the lowest thermal conductivity value of $0.11 \mathrm{~W} / \mathrm{mK}$, followed by $\mathrm{M} 2, \mathrm{M} 4$, and $\mathrm{M} 1$ with $0.65 \mathrm{~W} / \mathrm{mK}, 0.78 \mathrm{~W} / \mathrm{mK}$, and 0.83 $\mathrm{W} / \mathrm{mK}$, respectively. For variable samples M5, M6, M7, $\mathrm{M} 8$, and M9, the average value of thermal conductivity calculated gradually reduced from $0.77 \mathrm{~W} / \mathrm{mK}$ to 0.63 $\mathrm{W} / \mathrm{mK}$. From the result, a bar graph is presented as shown in Figure 16. M3 with 100\% of kenaf core was observed to have the lowest thermal conductivity value among all the samples studied. Compared to control sample M4, M9 recorded the lowest thermal conductivity value among the variable samples with a $19.2 \%$ reduction.

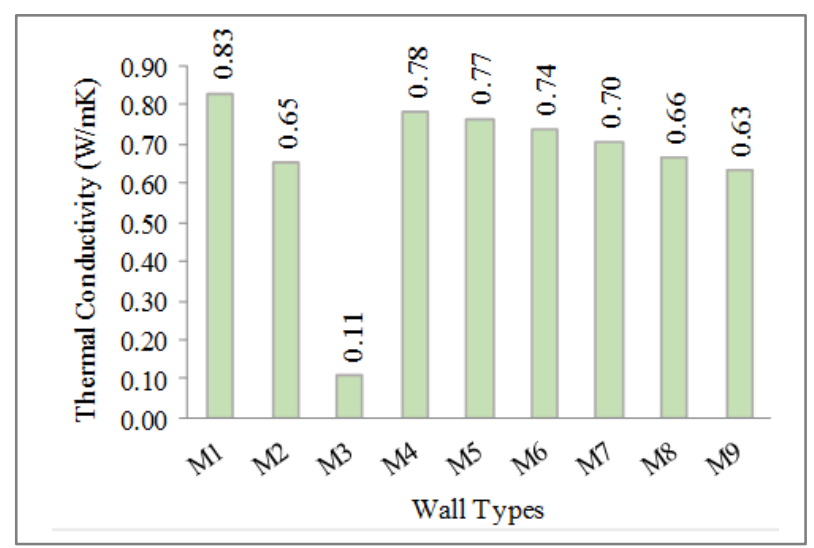

Figure 16. Thermal Conductivity of Brick Wall

Overall, the graph for the thermal conductivity of brick wall indicated the same pattern as the graph for the thermal conductivity of brick material but differed in thermal conductivity value. The differences are discussed in the next section.

\subsection{Thermal Conductivity of Brick Material and Thermal Conductivity of Brick Wall}

The thermal conductivity of brick material and brick 
wall was tested using different methods, but the objective was still to measure the thermal conductivity value. A bar chart for the thermal conductivity of brick material and thermal conductivity of brick wall was plotted and compared in Figure 17 based on the types of mix proportion. In general, the thermal conductivity value of the brick wall was observed to be a little bit higher than the thermal conductivity of brick material. This variance might have been caused by the width of the brick and varying plates. Besides that, the mortar joint between bricks might have affected the conductivity value because the material differed from the brick tested. Bricks with a low thermal conductivity value are needed to resist the heat from the outside temperature. The presence of the kenaf core helped in improving the thermal conductivity when compared to the conventional sand cement brick.

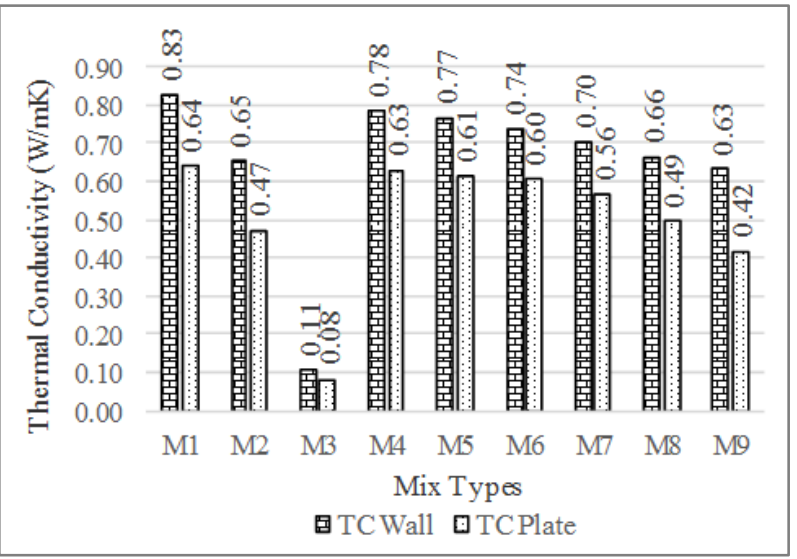

Figure 17. Thermal Conductivity of Material and Thermal Conductivity of Brick Wall

\subsection{Thermal Conductivity of Brick Wall versus Compressive Strength}

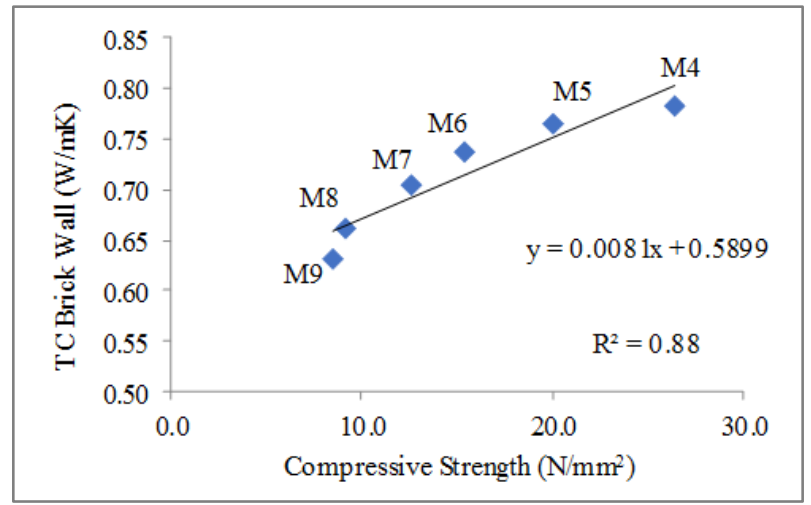

Figure 18. Thermal Conductivity of Brick Wall versus Compressive Strength

The correlation between the thermal conductivity of the brick wall and the compressive strength of brick wall is presented in Figure 18. From the linear graph, the $\mathrm{R}^{2}$ for this relationship was 0.88 and the coefficient of correlation was 0.94 . This indicated a very high correlation between thermal conductivity and compressive strength of KCQB wall. The higher the compressive strength, the higher the value of thermal conductivity, but with lower kenaf core content.

As mentioned earlier, the compressive strength for all types of bricks did fulfill the requirement of a structural brick. As for this study, the brick type, M9, was good enough to fulfill the aim of this study with low density, acceptable strength, and good thermal conductivity as well as usable waste product.

\subsection{Thermal Conductivity of Brick Wall versus Density}

The relationship between the thermal conductivity of the brick wall and the density of the bricks can be clearly seen by the linear graph presented in Figure 19. The $\mathrm{R}^{2}$ for this relationship was 0.91 , while the coefficient of correlation value was 0.95 . This reflected a very high correlation among both properties. The higher the density of the brick wall, the higher the value of thermal conductivity.

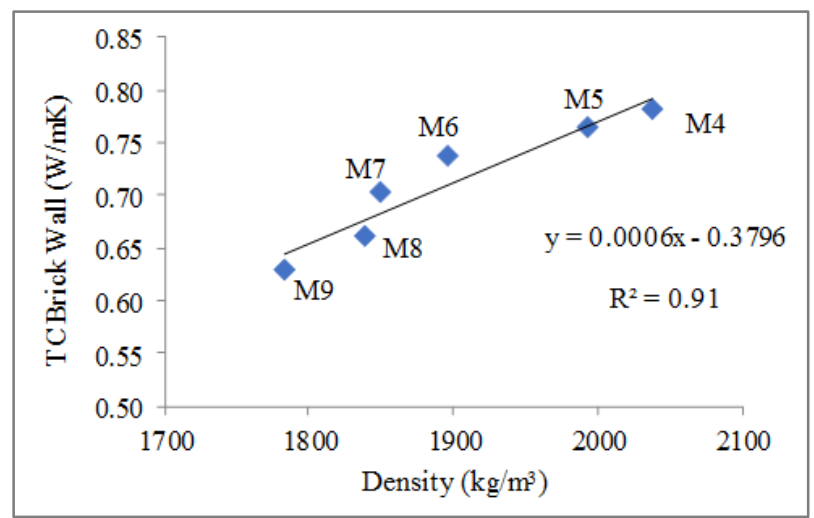

Figure 19. Thermal Conductivity of Brick Wall versus Density

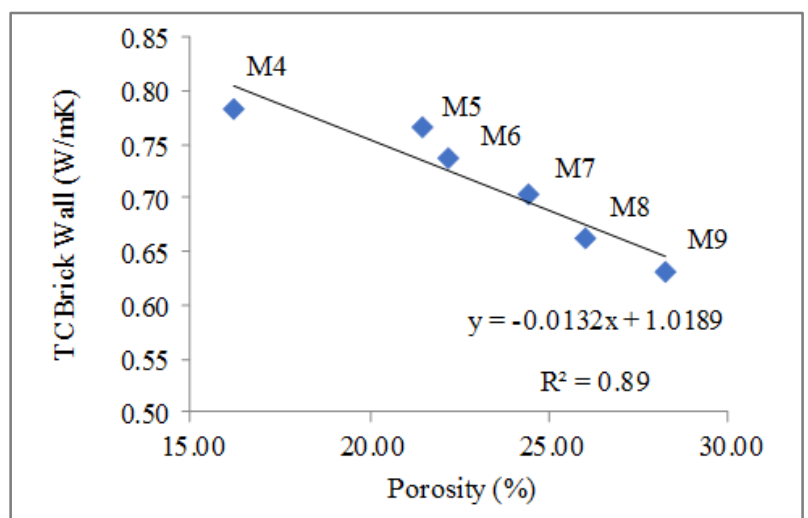

Figure 20. Thermal Conductivity of Brick Wall versus Porosity

Similar to the correlation discussed in Section 3.11 regarding the thermal conductivity of the brick material and porosity, the relationship between the thermal conductivity of the brick wall and porosity is presented in Figure 20 . From the linear graph, the $\mathrm{R}^{2}$ value was 0.89 , 
while the coefficient of correlation was 0.94. This represented a very high correlation between both parties. The lower the porosity, the higher the thermal conductivity value and vice versa. The thermal conductivities tend to decrease as a function of the percentage of the kenaf core, which is perfectly logical. The higher the percentage of the kenaf core content, the higher the amount of pores contained in the material, which is the cause of this decrease.

\section{Conclusions}

The compressive strength of the bricks containing a kenaf core decreased as the kenaf core increased. From the results of density, it can be concluded that the utilization of the kenaf core from $5 \%$ to $25 \%$ as sand replacement reduced the density of the bricks. Meanwhile, the increase in the kenaf core increased the porosity.

From the evaluation of the thermal conductivity of KCQB plates with different percentages of the kenaf core, it can be concluded that the higher percentage of the kenaf core in KCQB plates resulted in lower thermal conductivity values. The addition of the kenaf core from 5\% to $25 \%$ as sand replacement improved the thermal conductivity values from $0.63 \mathrm{~W} / \mathrm{m} \cdot \mathrm{K}$ to $0.42 \mathrm{~W} / \mathrm{m} \cdot \mathrm{K}$. The presence of the kenaf core with a highly microporous structure and spongy characteristic made the bricks lighter and could retain heat with low thermal conductivity values. The performance of thermal conductivity for the brick wall and brick material indicated the same trend, but the thermal conductivity of brick wall was slightly higher than the brick material.

It can be concluded that the addition of a kenaf core to KCQB enhanced the thermal conductivity performance with an advantage of a slight lightweight feature. Hence, there is a possibility to incorporate industrial and agricultural wastes into bricks with promising results as a thermal insulating material for buildings.

\section{Acknowledgments}

The authors would like to express their appreciation to Universiti Teknologi MARA and the National Kenaf and Tobacco Board, Malaysia for their assistance, co-operation and support in conducting this research.

\section{REFERENCES}

[1] N. Khalil and H. N. Husin. Post Occupancy Evaluation Towards Indoor Environment Improvement in Malaysia's Office Buildings, Journal of Sustainable Development, Vol. 2, pp. $186-191,2009$.

[2] A. M. Jalilluddin, S. M. Ayop, \& K. Kamaruddin.
Evaluation on the Thermal Conductivity of Sand-Cement Blocks with Kenaf Fiber. Advanced Materials Research, 626, 485-489, 2012.

[3] Cambridge Dictionary, Online available from https://dictionary.cambridge.org/dictionary/english/brick

[4] S. Ismail and Z. Yaacood. Properties of Bricks Produced with Recycle Fine Aggregate. World Academy of Science, Engineering and Technology 67, 2010.

[5] A. Elsaid, M. Dawood, R. Seracino, \& C. Bobko. Mechanical Properties of Kenaf Fiber Reinforced Concrete. Construction and Building Materials, 25(4), 1991-2001. 2011.

[6] S. H. Ahmad, R. Rasid, N. N. Bonnia, I. Zainol, A. A. Mamun, A. K. Bledzki \& M. D. H. Beg. Polyester-Kenaf Composites: Effects of Alkali Fiber Treatment and Toughening of Matrix Using Liquid Natural Rubber. Journal of Composite Materials, 45(2), 203-217. 2010.

[7] M. K. Razali \& J. M. Yatim. Mechanical Properties of Kenaf Fibrous for Brickworks, 280-292. 2015.

[8] R. Ilangovana, N. Mahendrana and K. Nagamani. Strength and Durability Properties of Concrete Containing Quarry Rock Dust (QRD) as Fine Aggregate. Journal of Engineering and Applied Sciences. 3(5): 20-26. 2008.

[9] K. Shyam Prakash \& C. H. Rao. Study on Compressive Strength of Quarry Dust as Fine Aggregate in Concrete. Advances in Civil Engineering, 1-52. 2016.

[10] Akinyemi, A. Banjo, Elijah, Alhassan, Oluwasegun, Aladegboye, Akpenpuun, T. Denen, Glory, Owolaja. The Use of Red Earth, Lateritic Soils and Quarry Dust As An Alternative Building Material in Sandcrete Block. Scientific African, 263. 2020.

[11] M. A. O. Mydin. Jurnal Teknologi Assessment of Thermal Conductivity, Thermal Diffusivity and Specific Heat Capacity of Lightweight Aggregate, 5, 477-482. 2016.

[12] E. Adam and P. Jones. Thermophysical Properties of Stabilised Soil Building Blocks, Build. Environ. 2, 245-253, 1995.

[13] T. Ashour, A. Korjenic, S. Korjenic, W. Wu. Thermal Conductivity of Unfired Earth Bricks Reinforced by Agricultural Wastes With Cement and Gypsum, Energy Build. 104, 139-146, 2015.

[14] N. A. Salehuddin, M. F. Arshad, N. Zakaria, A. H. Hassan, M. Z. Mohd Nor and N. M. Abdullah. Lignocelluloses Waste as Aggregate Replacement materials in Sand-Quarry Dust Cement Brick, International Congress on Innovations in Civil Engineering (ICE 2017), 2017.

[15] K. Kartini, N. E. Zainal Abidin, Noor, N.F. Baharuddin, A.F. Hamzah. Development of Lightweight Sand-Cement Bricks using Quarry Dust, Rice Husk and Kenaf Powder for Sustainability, International Journal of Civil \& Environmental Engineering IJCEE-IJENS Vol:12 No:06. 2012.

[16] K. Kartini, H. Ahmad Farhan, and U. Nor Azlina. Performance of sand cement bricks incorporating kenaf powder and rice husk ash, International Building and Infrastructure Technology Conference (BITECH 2011), Volume: Proceeding Book. 2011. 
[17] H.P.S. Abdul Khalil, A. F. Yusra, A.H. Irena Bhat, M. Jawaid. Cell wall ultrastructure, anatomy, lignin distribution, and chemical composition of Malaysian cultivated kenaf fiber. Ind. Crops Prod. 31(1):113-121, 2010.

[18] M. A. Fauzi, K. D. Abdul Ghani, H. Sulaiman, N. W. B. Azila. A Study on Kenaf Fibre Reinforced Concrete Block With Quarry Dust As Fine Aggregate Replacement, 2015.

[19] R. R. Krishnamoorthy \& T. K. David. Thermal Conductivity, Compressive Strength and Water Absorption
Of Recycled Coconut Fibre And Crushed Clay Brick Masonry. Jurnal Teknologi, 76 (11), 2015.

[20] A. S. Gandage, V. R.V. Rao, M. V. N. Sivakumar, A. Vasan, M. Venu \& A. B. Yaswanth. Effect of Perlite on Thermal Conductivity of Self Compacting Concrete. Procedia Social and Behavioral Sciences, 104, 188-197. 2013.

[21] M.A. Fauzi, M.F. Arshad, N.M. Nor. Statistical models to develop optimised controlled low-strength materials with wastepaper sludge ash, Construction and Building Materials, 286, 2021. 